\title{
A influência das ações de inclusão nos processos de resiliência de alunos da Educação Especial
}

The influence of inclusion actions in the resilience processes of Special Education students

La influencia de las acciones de inclusión en los procesos de resiliencia de alumnos de la Educación Especial

\author{
* Thais Watakabe Yanaga \\ Doutora pela Universidade Estadual Paulista, São Paulo, São Paulo, Brasil. \\ kawaiisaint@hotmail.com

\section{** Renata Maria Coimbra} \\ Professora doutora na Universidade Estadual Paulista, São Paulo, São Paulo, Brasil. \\ liborio@fct.unesp.br
}

Recebido em 11 de julho de 2018

Aprovado em 15 de abril de 2019

Publicado em 00 de junho de 2019

\section{RESUMO}

Este estudo teve como objetivo analisar como as ações de inclusão se articulam com processos de resiliência em adolescentes e jovens da Educação Especial, a partir da perspectiva dos alunos. O referencial teórico adotado se refere à abordagem socioecológica, cujos pressupostos dos estudos da resiliência se pautam, principalmente, numa abordagem cultural. Com relação à temática da inclusão, é entendida neste trabalho como um processo que valoriza as diferenças. A pesquisa de abordagem qualitativa foi realizada por meio de estudo de caso, que consistiu em pesquisa de campo, mais precisamente num estudo de caso múltiplo, que se realizou em seis campi do Instituto Federal do Paraná (IFPR). Buscou-se analisar a percepção dos alunos considerados em processo de resiliência sobre as ações de inclusão desenvolvidas no IFPR, como contribuindo para o processo de inclusão e para o bom crescimento dos alunos. Participaram deste estudo 12 alunos considerados em processo de resiliência. A partir dos dados coletados, as ações de inclusão citadas pelos alunosforam analisadas à luz das sete tensões da abordagem socioecológica, verificando por meio de suas resoluções ou não, o favorecimento de processos de resiliência. A partir dos dados coletados, as ações de inclusão citadas pelos alunosforam analisadas à luz das sete tensões da abordagem socioecológica, verificando por meio de suas resoluções ou não, o favorecimento de processos de resiliência. Os resultados apontaram que poucas ações de inclusão eram desenvolvidas institucionalmente, pois a maioria das ações era realizada por iniciativa 
própria dos professores e da equipe pedagógica. Conclui-se que por meio dessas ações, a maioria dos alunos da Educação Especial se sentiam incluídos, indicando que tais ações estavam favorecendo processos de resiliência, atuando como ações protetivas.

Palavras-chave: Processo de resiliência; Inclusão escolar; Educação Especial; Juventude.

\section{ABSTRACT}

This study aimed to analyze how inclusion actions are articulated with processes of resilience in adolescents and youngsters of Special Education, from the perspective of the students. The theoretical reference adopted refers to the socioecological approach, whose assumptions of resilience studies are mainly based on a cultural approach. Regarding the issue of inclusion, it is understood in this work as a process that values differences. The qualitative research was carried out through a case study, which consisted of field research, more precisely in a multiple case study, which was carried out in six campuses of the Federal Institute of Paraná (IFPR). We sought to analyze the perception of the students considered in the process of resilience on the inclusion actions developed in the IFPR, as contributing to the inclusion process and to the good growth of the students. Twelve students considered in the process of resilience participated in this study. From the collected data, the inclusion actions cited by the students were analyzed in the light of the seven tensions of the socioecological approach, verifying through their resolutions or not, the favoring of resilience processes. From the collected data, the inclusion actions cited by the students were analyzed in the light of the seven tensions of the socioecological approach, verifying through their resolutions or not, the favoring of resilience processes. The results showed that few inclusion actions were institutionally developed, since most of the actions were carried out on the initiative of the teachers and the pedagogical team. It was concluded that through these actions, most Special Education students felt included, indicating that such actions were favoring resilience processes, acting as protective actions.

Keywords: Resilience process; School inclusion; Special education; Youth.

\section{RESUMEN}

Este estudio tuvo como objetivo analizar cómo las acciones de inclusión se articulan con procesos de resiliencia en adolescentes y jóvenes de la Educación Especial, desde la perspectiva de los alumnos. El referencial teórico adoptado se refiere al abordaje socioeconómico, cuyos presupuestos de los estudios de la resiliencia se basan principalmente en un enfoque cultural. Con respecto a la temática de la inclusión, se entiende en este trabajo como un proceso que valora las diferencias. La investigación de abordaje cualitativo fue realizada por medio de un estudio de caso, que consistió en investigación de campo, más precisamente en un estudio de caso múltiple, que se realizó en seis campus del Instituto Federal de Paraná (IFPR). Se buscó analizar la percepción de los alumnos considerados en proceso de resiliencia sobre las acciones de inclusión desarrolladas en el IFPR, como contribuyendo al proceso de inclusión y al buen crecimiento de los alumnos. Participaron de este estudio 12 alumnos considerados en proceso de 
resiliencia. A partir de los datos recolectados, las acciones de inclusión citadas por los alumnos se analizaron a la luz de las siete tensiones del abordaje socioeconómico, verificando por medio de sus resoluciones o no, el favorecimiento de procesos de resiliencia. A partir de los datos recolectados, las acciones de inclusión citadas por los alumnos se analizaron a la luz de las siete tensiones del abordaje socioeconómico, verificando por medio de sus resoluciones o no, el favorecimiento de procesos de resiliencia. Los resultados apuntaron que pocas acciones de inclusión eran desarrolladas institucionalmente, pues la mayoría de las acciones eran realizadas por iniciativa propia de los profesores y del equipo pedagógico. Se concluye que por medio de esas acciones, la mayoría de los alumnos de Educación Especial se sentían incluidos, indicando que tales acciones estaban favoreciendo procesos de resiliencia, actuando como acciones protectivas.

Palabras clave: Proceso de resiliencia; Inclusión escolar; Educación Especial; La juventud.

\section{Introdução}

O processo de inclusão passou a se concretizar com a propagação do entendimento da deficiência como condição social, no qual a sociedade passou a questionar o conceito de "normalidade" e uniformidade imposta, pois a verdadeira condição da sociedade humana é estruturada na diversidade, sendo composta por pessoas todas diferentes entre si, com suas qualidades, potencialidades e também deficiências (GALVÃO FILHO, 2009).

Esse novo paradigma nos traz a ideia de que a pessoa com deficiência tenha respeitadas suas diferenças, uma vez que a sociedade deve se transformar buscando 0 ideal da valorização das diferenças, retirando as barreiras existentes para que a participação da pessoa com deficiência realmente aconteça, convertendo-se em uma sociedade inclusiva que busca tornar acessível todas as suas realidades, garantindo todos os direitos e deveres de cidadão à pessoa com deficiência (GALVÃO FILHO, 2009).

Assim, entendendo a inclusão como um processo histórico e social, podemos perceber a influência desse processo na vida contemporânea das pessoas com deficiência nos seus contextos sociais, enfocando a questão no ambiente escolar.

Atualmente, a possibilidade de educação da pessoa com deficiência de forma inclusiva ainda está em processo, pois para que seja possível a promoção de uma concepção de educação que valorize as diferenças entendemos ser preciso que a instituição escolar se modifique, desvinculando-se de um modelo padronizado que se caracteriza pela homogeneização. Nesse contexto escolar, o repasse massificado de informações, o uso da prática da memorização, além da não consideração das diferenças individuais entre os alunos, geram a exclusão escolar (GALVÃO FILHO, 2009). "Aquele que 
não se enquadra nos perfis de normalidade e não dá a resposta padrão esperada é imediatamente penalizado, com a reprovação ou com a exclusão, ou com a falta de aprendizado" (GALVÃO FILHO, 2009, p. 67).

Segundo Sartoretto (2011) para que a inclusão possa acontecer, fundamentando-se no direito do ser humano viver e conviver com outros seres humanos, sem discriminação e sem segregações, é indispensável, primeiramente, que as escolas destituam-se das práticas de ensino tradicionais, sendo então possível colocar em prática o que se encontra nas normativas sobre inclusão. Mantoan et al. (2011, p.7) também concorda que "a escola inclusiva deve ter como fundamento o reconhecimento das diferenças dos alunos diante do processo educativo e a busca pela participação e pelo progresso de todos, adotando novas práticas pedagógicas". Porém, o uso dessas novas práticas, depende de mudanças que vão além da sala de aula. É necessário o desenvolvimento de novos conceitos e práticas pedagógicas que busquem a inclusão decorrentes da vontade de um coletivo escolar.

Dentre os documentos que fundamentam a educação inclusiva, destacamos a Política Nacional de Educação Especial na Perspectiva da Educação Inclusiva (BRASIL, 2008). Este documento define quem serão os estudantes Público Alvo da Educação Especial (PAEE), sendo aqueles com impedimentos de longo prazo, de natureza física, mental, intelectual ou sensorial, que em interação com diversas barreiras podem ter restringida sua participação plena e efetiva na escola e na sociedade; os alunos com transtornos do espectro autista (TEA) (BRASIL, 2012), que são aqueles que apresentam alterações qualitativas das interações sociais recíprocas e na comunicação, um repertório de interesses e atividades restrito, estereotipado e repetitivo. E também são considerados PAEE os estudantes com altas habilidades/superdotação que demonstram potencial elevado em qualquer uma das seguintes áreas, isoladas ou combinadas: intelectual, acadêmica, liderança, psicomotricidade e artes. Também apresentam elevada criatividade, grande envolvimento na aprendizagem e realização de tarefas em áreas de seu interesse.

Dessa forma, a inclusão escolar de pessoas PAEE não se refere apenas às questões de acessibilidade física e estrutural, nem de adaptações de materiais didáticos ou curriculares, vai muito além. Refere-se ao desenvolvimento de uma cultura escolar que valorize a diferença, que faça com que a pessoa PAEE se sinta bem naquele ambiente, que ela seja vista pelas suas potencialidades e não pela sua limitação. "A educação inclusiva concebe a escola como um espaço de todos, no qual os alunos constroem o 
conhecimento segundo suas capacidades, expressam suas ideias livremente, participam ativamente das tarefas de ensino e se desenvolvem como cidadãos, nas suas diferenças" (MANTOAN et al., 2011, p.5-6).

Assim, o objetivo principal deste estudo foi entender de que forma as ações de inclusão escolar implementadas pelas instituições de ensino estavam contribuindo para o bom crescimento ${ }^{1}$ dos alunos PAEE, oferecendo apoio e suporte, e favorecendo o processo de inclusão na escola. Esse bom crescimento, proporcionado pela superação de situações adversas, é conhecido como processo de resiliência, pois segundo Ungar (2007, p.2, tradução nossa ${ }^{2}$ ) o processo de resiliência é resultante das "oportunidades que crianças e adolescentes têm de acessar apoios psicológicos, emocionais, relacionais e instrumentais que precisam para crescer bem, enquanto vivendo sob circunstâncias adversas”. Portanto, a resiliência se refere ao "resultado de um enfrentamento e superação de algo significativamente apontado como de risco pelo sujeito" (PESSOA, 2011, p.29). Assim, para compreendermos a resiliência, precisamos entender sobre fatores de risco e proteção.

\section{Resiliência e Fatores de Risco e Proteção}

Para Libório (2011) os fatores de risco e proteção são importantes quando estudamos processos de resiliência, pois a autora considera necessário verificar a presença de experiências que apresentam riscos crescentes ao desenvolvimento do indivíduo, assim como verificar os fatores de proteção. "A diferença entre mecanismos de risco e processos de proteção reside no fato de que o risco leva o indivíduo a apresentar desordens de diversos níveis, enquanto proteção atua positivamente sobre as variáveis de risco por meio de suas interações" (LIBÓRIO, 2011, p.31).

Sobre os fatores de risco, é preciso esclarecer que estes não são sinônimos de indicadores ou condições de risco, ou seja, muitos indicadores ou condições de risco como pobreza, abuso físico, desastres, guerras poderiam indicar um risco em si, por já se prever as consequências negativas para as pessoas que os vivenciam (YUNES; SZYMANSKI,

\footnotetext{
${ }^{1}$ Entende-se que o conceito de "crescer bem" não pode ser compreendido de forma idealizada e muito menos padronizada, pois para avaliar o "crescer bem", deve-se compreender "conjuntamente a gravidade da exposição ao risco e o comportamento do adolescente, pois devemos focar a relação entre gravidade enfrentada e nível do salto conseguido" (LIBÓRIO, 2011, p. 139).

${ }^{2}$ It will argue that resilience as an outcome emerges, at least in part, from the opportunities children have to access the psychological, emotional, relational, and instrumental supports they need to thrive while growing up under adverse circumstances (UNGAR, 2007, p2).
} 
2001). Porém o indicador de risco só poderá ser considerado como um fator de risco se interferir negativamente no bom crescimento do indivíduo e for apontado pelo sujeito como um risco. Yunes e Szymanski (2001) ressaltam que riscos devem ser pensados como processos, associados aos dinamismos e relatividade e não como algo, a priori, concebido como determinista, ou seja, situações que são consideradas de riscos para algumas pessoas podem não ser para outras, pois depende do contexto e do momento que a pessoa está vivenciando.

Já os fatores de proteção, de acordo com Yunes e Szymanski (2001) ainda dizem respeito às influências que modificam, melhoram ou alteram respostas pessoais a determinados riscos, evitando que os indivíduos expostos a riscos tenham seu desenvolvimento prejudicado, o que também deve ser visto de forma processual. Assim, os fatores de proteção são o conjunto de recursos internos e externos que o indivíduo possui para realizar uma resposta positiva no confronto de vários acontecimentos de riscos. Os recursos internos não podem ser considerados como inatos ao sujeito, pois são decorrentes dos fatores de proteção que o contexto social e cultural assegurou. $O$ produto final da interação entre fatores de risco e proteção associa-se diretamente com os processos de resiliência (LIBÓRIO, 2009).

No caso dos alunos PAEE, as dificuldades que enfrentam decorrentes de suas características específicas podem ser consideradas como fatores de risco e as ações de inclusão escolar, o apoio dos amigos, professores e familiares como fatores de proteção, segundo a literatura estudada (CATUSSO, 2007; SCHMIDT et al, 2007; SIMÕES et al., 2010; FEE; HILTON, 2011; MIGERODE et al., 2012; CARDOSO; SACOMORI, 2014; LIBÓRIO et al., 2015).

Defendemos que as ações de inclusão escolar deveriam configurar-se como atos de proteção ao adolescente e jovem PAEE, uma vez que oportunizariam maior participação social, pois a convivência interpessoal que busca respeitar as diferenças estimula 0 surgimento de vínculos afetivos, o desenvolvimento da consciência sobre os direitos e responsabilidades, como também para o conhecimento de suas potencialidades.

$\mathrm{O}$ estudo do processo de resiliência em adolescentes e jovens PAEE por meio das ações de inclusão teve como referencial a abordagem socioecológica de Michael Ungar, que desenvolve estudos sobre a resiliência baseado na perspectiva cultural. Esse 
referencial entende que o desenvolvimento e a promoção dos fatores de proteção interno e externo do indivíduo é resultado do envolvimento deste com sua cultura e contexto.

Para Ungar et al. (2007) a cultura tem uma grande contribuição nos processos relacionados à resiliência, já que as necessidades para o bom crescimento do indivíduo são negociadas através das e entre as culturas. Portanto, o sujeito que é considerado em processo de resiliência em certo contexto cultural, pode não ser visto da mesma forma em outra cultura.

A partir da abordagem socioecológica, Ungar com outros pesquisadores realizaram um estudo com adolescentes em situação de risco, no qual se elucidou a presença de sete tensões que, ao serem resolvidas de maneiras diferentes pelos adolescentes, auxiliavam no bom crescimento psicossocial, associado com bem-estar e resiliência, de acordo com critérios de suas culturas e contextos. Segundo Ungar et al. (2007) são consideradas como as sete tensões:

Acesso a recurso material: refere-se à possibilidade do indivíduo acessar recursos sociais que garantam assistência financeira e a concretização de necessidades básicas como educação e trabalho, necessidades que variam de acordo com o contexto e cultura.

Justiça social: refere-se à capacidade de reivindicar seus direitos, seja um direito pessoal ou coletivo. Vivência de situações de injustiça e preconceito "funcionam como catalizadores de conscientização, resistência, solidariedade, crença em um poder espiritual e enfrentamento da opressão; essa tensão se relaciona com as experiências de encontrar um papel significativo na sociedade" (LIBÓRIO, 2011, p.36).

Relacionamentos: refere-se aos relacionamentos interpessoais significativos que oferecem apoio e suporte emocional, podendo ser composto por membros familiares, grupo de pares, pessoas da comunidade, professores.

Identidade: se relaciona à percepção do indivíduo sobre suas habilidades e limites, sendo que o processo de formação de identidade é uma co-construção por meio de interações em espaços discursivos mútuos;

Coesão: essa tensão promove interação entre o eu (individual) com o coletivo de forma a cumprir as expectativas da comunidade e da cultura, há a necessidade de estabelecer uma relação entre o senso pessoal de responsabilidade com o dever e compromisso com a comunidade. 
Poder e controle: Refere-se à capacidade interior e aos recursos ao redor que as pessoas possuem para tomada de decisões. Relaciona-se à capacidade de cuidar de si próprio e de promover mudanças nos ambientes sociais e físicos que assegurem os recursos e relacionamentos de que se necessite;

Aderência cultural: "refere-se à capacidade de aderir - ou ficar em oposição - às normas culturais, crenças e valores de sua comunidade, o que implica negociações complexas com os cuidadores e comunidades" (LIBÓRIO, 2011, p. 36).

Consideramos que os estudos sobre resiliência e inclusão escolar têm importância fundamental para a área da educação, pois permitem uma reflexão sobre a realidade e as necessidades dos alunos PAEE no ambiente escolar, favorecendo ações que permitam um bom crescimento.

\section{Metodologia}

Como buscamos compreender a inclusão e a resiliência enquanto processos dinâmicos que se desenvolvem por meio das relações sociais e culturais, o caminho metodológico foi conduzido por meio da abordagem qualitativa, utilizando o estudo de caso.

\section{Local da Pesquisa}

A pesquisa foi realizada no IFPR - Instituto Federal do Paraná. As instituições de ensino federais estão ligadas à Ação Tecnologia, Educação, Cidadania e Profissionalização para Pessoas com Necessidades Específicas (TEC NEP). Essa ação busca desenvolver uma política pública inclusiva e tem como proposta a implantação do Núcleo de Atendimento as Pessoas com Necessidades Educacionais Específicas (NAPNE) nas instituições de ensino para que seja possível fomentar o desenvolvimento de ações que criem condições de acesso e permanência aos alunos PAEE.

O IFPR atualmente é composto por 20 campi e 5 campi avançados; desse total, somente 13 campus (Assis Chateaubriand, Campo Largo, Curitiba, Foz do Iguaçu, Irati, Ivaiporã, Jacarezinho, Londrina, Palmas, Paranaguá, Paranavaí, Telêmaco Borba, Umuarama) possuíam, na época do levantamento das informações (segundo semestre de 2015), o NAPNE oficializado com reconhecimento no site do Ministério de Educação (MEC) (BRASIL, 2012b).

Em virtude da metodologia escolhida para esta pesquisa, que nos exigiria o deslocamento a várias cidades diferentes em mais de um momento, preferimos convidar 
para participar da pesquisa, dentre os campi com o NAPNE oficializado, somente aqueles com distância inferior a $400 \mathrm{~km}$ da nossa moradia. Portanto, de um total de 13 campus, participariam da pesquisa sete, porém o campus Ivaiporã não possuía matrículas de alunos PAEE na época, assim, ao final participaram da pesquisa seis campi (Assis Chateaubriand, Jacarezinho, Londrina, Paranavaí, Telêmaco Borba, Umuarama).

A parceria com os campi aconteceu por meio do contato via e-mail e telefone com os coordenadores do NAPNE de cada campus, por meio do qual solicitamos um levantamento entre o segundo semestre de 2015 e meados de 2016 do número de alunos PAEE atendidos em cada campus.

\section{Critérios de Seleção}

Definimos que, para participar do estudo, os alunos deveriam: a) ser considerados PAEE como indicado na Política Nacional de Educação Especial na Perspectiva da Educação Inclusiva (BRASIL, 2008); b) estar estudando no IFPR; c) ter recebido avaliação de "crescer bem" pelos professores; d) aceitar e assinar o termo de consentimento livre e esclarecido (TCLE) dos participantes maiores de idade e dos pais ou responsáveis no caso dos alunos menores de idade (estes também deveriam assinar o Termo de Assentimento); e) estar na faixa etária de 14 a 29 anos, independente do sexo, por se tratar de adolescentes matriculados no Ensino Médio, como também por se tratar de jovens matriculados no Ensino Superior. Ressaltamos que a Política Nacional da Juventude (PNJ) considera como jovens as pessoas com até 29 anos.

\section{Participantes}

A seleção dos alunos PAEE considerados em processo de resiliência foi feita pelos seus professores (foram convidados os professores que dessem ou já tivessem dado aula para todos os alunos PAEE do seu campus - esse levantamento foi feito pelos coordenadores do NAPNE), a importância dos professores participantes terem contato com todos os alunos PAEE do seu campus era necessária para que definissem o significado de "crescer bem" para eles e pudessem, a partir dessa referência, distinguir entre os alunos PAEE com que tinham contato, aqueles que consideravam como crescendo bem, daqueles que não consideravam. Essa estratégia de seleção dos alunos pelos profissionais foi baseada nas pesquisas realizadas por Ungar e Libório (2013), Ungar (2007, 2011) e Libório 
(2011, 2015), que estudavam processos de resiliência em adolescentes em situação de risco.

A avaliação dos professores sobre o que entendiam por "crescer bem", aconteceu por meio de uma conversa coletiva com os professores de cada campus que aceitaram participar, na qual eles expunham sua compreensão sobre o conceito de crescer bem frente às adversidades (tais como barreiras arquitetônicas e atitudinais), considerando os alunos PAEE. Embora não seja o objetivo da pesquisa analisar tais critérios, consideramos necessário salientar a presença de duas concepções distintas desse "crescer bem": uma delas apontava mais a influência do contexto (família e escola), auxiliando no processo de inclusão, associado ao "crescer bem"; e outra concepção, que enfatizava mais uma dimensão pessoal, em que os alunos não viam a deficiência como um problema nem se posicionavam como vítimas.

Os alunos PAEE considerados pelos professores como crescendo bem foram convidados presencialmente a participarem da pesquisa, sendo que todos concordaram em participar. Assim, segue quadro com os alunos participantes, cujos nomes são fictícios e foram escolhidos por eles.

Quadro 1 - Alunos participantes da pesquisa de campo

\begin{tabular}{|c|c|c|c|c|c|}
\hline Aluno & Campus & Idade & $\begin{array}{l}\text { Tempo de IFPR } \\
\text { na época da } \\
\text { entrevista }\end{array}$ & $\begin{array}{l}\text { Características } \\
\text { Específica }\end{array}$ & $\begin{array}{l}\text { Modalidade } \\
\text { de Ensino }\end{array}$ \\
\hline Maria & Assis Chateaubriand & 14 & 4 meses & Física- Raquitismo & Ensino Médio \\
\hline Thiago & Assis Chateaubriand & 16 & 1 ano e 4 meses & Síndrome de Asperger & Ensino Médio \\
\hline Franklyn & Jacarezinho & 15 & 6 meses & Cego & Ensino Médio \\
\hline Luan & Londrina & 27 & 6 meses & Síndrome de Down & $\begin{array}{l}\text { Técnico } \\
\text { Subsequente } \\
\text { ao Ensino } \\
\text { Médio }\end{array}$ \\
\hline Catarina & Londrina & 15 & 6 meses & $\begin{array}{l}\text { Física } \\
\text { Mielomeningocele }\end{array}$ & Ensino Médio \\
\hline Willian & Londrina & 15 & 6 meses & Deficiência Visual & Ensino Médio \\
\hline Julia & Paranavaí & 16 & 1 ano e 4 meses & Surda & Ensino Médio \\
\hline Allan & Paranavaí & 26 & 4 meses & Surdo & $\begin{array}{l}\text { Ensino } \\
\text { Superior }\end{array}$ \\
\hline João & Telêmaco Borba & 19 & 6 meses & Síndrome de Asperger & $\begin{array}{l}\text { Ensino } \\
\text { Superior }\end{array}$ \\
\hline
\end{tabular}




\begin{tabular}{|l|l|l|l|l|l|}
\hline Dhiego & Telêmaco Borba & 25 & 6 meses & Surdo & Ensino Médio \\
\hline Fabio & Umuarama & 28 & 1 ano e 4 meses & Surdo & $\begin{array}{l}\text { Ensino } \\
\text { Superior }\end{array}$ \\
\hline Zé & Umuarama & 28 & 4 meses & $\begin{array}{l}\text { Física - amputação } \\
\text { braço }\end{array}$ & $\begin{array}{l}\text { Ensino } \\
\text { Superior }\end{array}$ \\
\hline
\end{tabular}

Fonte: Pesquisa de campo, 2016.

\section{Instrumentos}

Nesta pesquisa, utilizamos a entrevista semiestruturada e métodos visuais (fotografia).

A Entrevista Semiestruturada foi realizada no dia agendado com os alunos, momento durante o qual a pesquisadora fez as perguntas de acordo com o roteiro de questões e os alunos puderam falar livremente. As entrevistas foram gravadas e duraram em média 40 minutos. O roteiro das perguntas foi elaborado de acordo com bibliografia estudada, relacionando com as categorias das sete tensões, tendo como objetivo verificarmos quais ações de inclusão eram evidenciadas pelos alunos participantes e como contribuíam para sua vida. As entrevistas com os alunos aconteceram entre maio e setembro de 2016.

Outro instrumento utilizado com os alunos foi o método visual (foto-elicitação), no caso as fotografias. Dos doze alunos participantes da entrevista semiestruturada, seis (Thiago, Franklyn, Catarina, Willian, Julia, Fabio) decidiram continuar participando e os outros seis optaram por não participar do segundo momento da pesquisa de campo. Três deles alegaram que não queriam dar continuidade, outros dois por não gostarem de fotografias e um por considerar que estava sobrecarregado de afazeres no trabalho e na escola.

Pedimos aos alunos que tirassem fotos utilizando a câmera do seu aparelho celular (durante a entrevista semiestruturada verificamos que todos os alunos possuíam celular). Explicamos aos alunos que deveriam tirar fotos de momentos, ações, espaços ou pessoas que eles consideravam como tendo influências positivas e/ou negativas em suas vidas no IFPR, de 15 a 20 fotos em um período de 15 dias. Após esse procedimento, os alunos enviaram por e-mail as fotos tiradas e foi agendado um dia para conversarmos presencialmente sobre as fotos. Durante a entrevista sobre as fotos, estas foram observadas no computador e os alunos explicaram o motivo da escolha da foto, o que ela representava, ou seja, os alunos interpretaram a foto. Esse instrumento nos permitiu verificar pessoas, lugares e momentos que faziam os alunos se sentirem bem ou não, no 
contexto escolar, podendo confirmar os dados da entrevista semiestruturada como também apresentar novos dados que não foram ditos na entrevista, uma vez que as fotografias permitem trazer muitas informações implícitas. Esse instrumento foi aplicado em outubro de 2016.

\section{Análise dos dados}

Como a fundamentação teórica deste trabalho se baseia na abordagem socioecológica, consideramos como categorias para análise dos dados obtidos com os alunos as próprias tensões (acesso a recursos materiais, Identidade, Coesão, Relacionamentos, Poder e Controle, Justiça Social e Aderência cultural) apresentadas por Ungar (2007), e que se articulam com processos de resiliência. Assim, tínhamos categorias analíticas a priori como fio condutor da discussão dos dados da pesquisa.

Vale ressaltar neste momento, que apesar dos alunos participantes pertencerem a vários campi diferentes, preferimos categorizar as ações de inclusão (que entendemos como aquelas que possibilitam a participação ativa de todos os alunos nas atividades de ensino, respeitando suas diferenças), de forma institucional e não por campus, uma vez que, apesar de cada campus possuir a sua realidade, sendo caracterizados pelos servidores e alunos que os compõem, todos são geridos pelo mesmo regimento e devem seguir as mesmas orientações institucionais. Assim também, quando houver referência às ações institucionais, estas referem-se às práticas que são desencadeadas pela Reitoria do IFPR, por meio das Pró-reitorias e diretorias competentes. Dessa forma, verificamos as contribuições das ações de inclusão da instituição IFPR no processo de resiliência dos alunos PAEE.

\section{Resultados e Discussão}

Apresentamos os resultados e a discussão a partir de categorias analíticas a priori, de acordo com as sete tensões da abordagem socioecológica, apresentando subcategorias definidas pelas ações de inclusão destacadas pelos alunos PAEE.

\section{Acesso a recursos materiais}

Nesta categoria analisamos os recursos que foram citados pelos alunos PAEE como meios que contribuem para a acessibilidade no espaço escolar. Por acessibilidade, entendemos como a quebra de barreira ou qualquer entrave ou obstáculo que limite ou impeça o acesso, a liberdade de movimento, a circulação com segurança e a possibilidade 
de as pessoas se comunicarem ou terem acesso à informação (BRASIL, 2004). Como na pesquisa de Didkowsky et al. (2010), que estudaram processos de resiliência em adolescentes em situação de risco, além das estruturas físicas, os serviços oferecidos pela comunidade também foram enquadrados como meios que permitiam o acesso aos recursos materiais. Assim, nesta pesquisa, além dos recursos físicos, também levamos em consideração os recursos humanos e os atendimentos ofertados que oportunizavam a acessibilidade aos alunos com deficiência.

\section{Infraestrutura: acessibilidade física e adequação/organização do espaço}

Segundo Schmidt et al. (2007) os componentes objetivos (bens materiais concretos) são importantes para a manutenção da qualidade de vida de pessoas com deficiência, como no caso da incapacidade de mobilidade, no qual a acessibilidade física e estrutural contribuem para a qualidade de vida destas pessoas.

Com relação à infraestrutura, os alunos mencionaram existir estruturas destinadas mais para a deficiência física, como elevador e rampa. Para as demais deficiências que também necessitam de adequações estruturais, o IFPR as oferecia parcialmente, como citado pelo aluno Franklin (cego) no qual o piso tátil só existia no ambiente externo, na parte interna não havia direcionamento para as salas de aula ou banheiro. Ou então não eram oferecidas, como pontuada pela aluna Julia (surda) como a falta de um sinal visual.

$\mathrm{Na}$ percepção dos alunos, a partir das fotografias (Figura 1), a biblioteca e os laboratórios apareceram como espaços que os alunos valorizavam, pelo fato da instituição oferecer esses espaços de forma adequada. Para os alunos, a biblioteca possui um bom acervo e bons equipamentos, e é um espaço com acessibilidade, não havendo restrições para seu uso.

Figura 1 - A biblioteca pelo olhar de Catarina

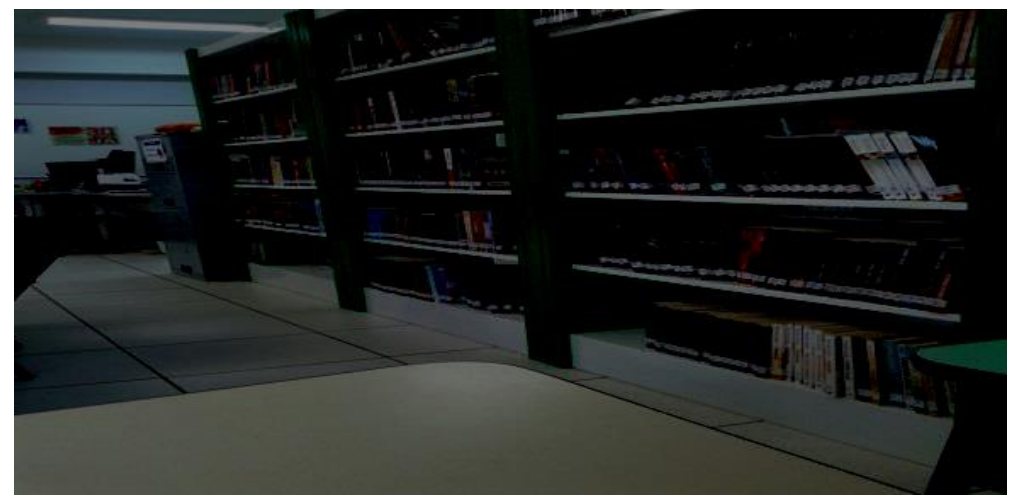

Fonte: Pesquisa de Campo, 2016. 
Ressaltamos que os alunos entrevistados não fotografaram os espaços que demonstravam explicitamente a inclusão, como o elevador, a rampa, o piso tátil, o banheiro adaptado, mas sim espaços comuns que, por representarem algo bom, consideramos que os fazem sentirem incluídos. É importante levar em consideração o referencial contextualizado da população em estudo (PESSOA, 2011), pois nesse caso, os alunos com deficiência valorizaram situações comuns do espaço escolar que se tornaram importantes, uma vez que nessas situações consideraram-se mais incluídos do que em situações destinadas especificamente a eles e que, por isso, poderiam acabar "diferenciando-os".

\section{Recursos didáticos: adaptações para $o$ aprendizado}

A maioria dos alunos consideraram que estavam sendo contemplados no que diz respeito aos materiais didáticos que ajudavam na sua acessibilidade. Somente Dhiego e Julia (surdos) citaram que o IFPR não estava ofertando os materiais necessários. No caso, a aluna solicitou o uso de legendas nos vídeos assistidos em sala de aula, embora poucos professores tenham feito essa adequação, levando-a a ter que dividir sua atenção entre a imagem do vídeo e a interpretação da intérprete de Língua Brasileira de Sinais (LIBRAS). Para o aluno Dhiego, que possui dificuldades em ler o português, faltam materiais acessíveis como vídeos sobre os conteúdos que aprendem, em LIBRAS.

Algo interessante promovido pelos professores foi incluir os demais alunos no desenvolvimento de materiais didáticos acessíveis. Muitos materiais didáticos que o aluno Franklyn, cego, utiliza foram desenvolvidos pelos seus colegas de classe, em função das necessidades do aluno e contribuíram para sua aprendizagem e para a disseminação de práticas inclusivas.

\section{Recursos Humanos e os atendimentos ofertados}

A acessibilidade não se limita apenas à questão estrutural e de materiais didáticos, refere-se também à acessibilidade relativa à aprendizagem, por meio do uso de recursos que permitam a comunicação e deem acesso às informações. Nessa questão, a maioria dos alunos alegaram que os professores seriam os recursos humanos que apreciam muito, pela busca do aprendizado, qualificação e forma de ensinar os alunos com dificuldades. Porém para os alunos surdos falta intérprete de LIBRAS e professores com metodologias condizentes às suas necessidades.

Segundo Jones (2011) a atuação dos professores que buscam tornar a sala de aula um ambiente de proteção, ajudando os alunos com suas dificuldades e contribuindo para o 
sucesso escolar desenvolve o processo de resiliência educacional que se refere a atitudes positivas com relação às realizações acadêmicas.

Além dos professores, os atendimentos existentes no IFPR também são considerados pelos alunos PAEE como meios que ajudam na sua aprendizagem, dentre os citados pelos alunos verificamos que existem atendimentos que não são exclusivos a eles, que podem ser usufruídos por todos os alunos do IFPR. Como exemplo, atividades domiciliares e atendimentos acadêmicos. Este faz parte da normativa do IFPR, no qual, o professor reserva 4 horas da sua carga horária para dar atendimento em outros horários aos alunos, momento em que pode retomar o conteúdo trabalhado em sala de aula ou tirar as dúvidas dos alunos.

Os alunos também citaram atendimentos específicos a eles como reforço acompanhado da pedagoga, adaptações em aula de laboratório, aulas de português para alunos surdos.

Pelas fotografias, o aluno Franklyn fotografou o seu aprendizado com o soroban que, no caso, tratava-se de um curso ofertado pelo professor de matemática do IFPR aos alunos e à comunidade externa sobre o uso do soroban no aprendizado de matemática. Para o aluno, o registro (Figura 2) representa a foto que mais gostou, pois antes do curso, como ele não sabia trabalhar com o instrumento, não gostava de utilizá-lo. Atualmente, após o curso e com a prática, está gostando.

Figura 2 - Aprendendo a utilizar o soroban pelo olhar do Franlyn

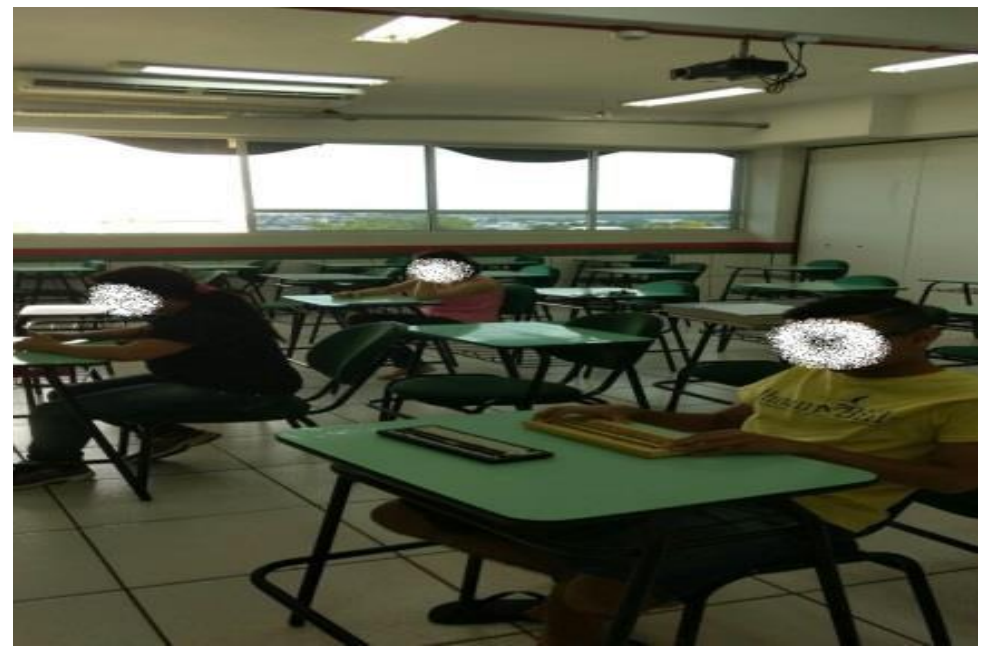

Fonte: Pesquisa de campo, 2016.

Além dos atendimentos, o IFPR disponibiliza diversos tipos de auxílios financeiros aos alunos em vulnerabilidade socioeconômica, como o PBIS - Programa de Bolsa de Inclusão 
Social, PACE - Programa de Auxílio Complementar ao Estudante e a Bolsa Atleta. O IFPR também oferece bolsas de pesquisas aos alunos que, nesse caso, são selecionados pelos coordenadores da pesquisa em decorrência do perfil e desempenho acadêmico do aluno. Tais auxílios financeiros contribuem para o transporte e alimentação dos alunos, principalmente nos casos em que estes permanecem na instituição em mais de um período, como para os atendimentos dos professores no contraturno.

O aluno Thiago, no ano de 2016, quando realizamos a entrevista, o mesmo não havia sido contemplado com nenhum tipo de auxílio financeiro e dentre as fotografias que tirou, escolheu como uma foto de que menos gostou a foto de uma coxinha (Figura 3). Na entrevista sobre as fotos, ele explicou que na verdade a foto representava algo de que não gostava, pois não tinha dinheiro no momento para comprar uma refeição, uma vez que no ano da entrevista o aluno não havia sido contemplado com nenhum tipo de bolsa ou auxílio. Podemos entender que o auxílio financeiro por parte da instituição contribui para o bemestar dos alunos, que no caso do aluno Thiago consistia na sua alimentação durante o período escolar.

Figura 3 - A coxinha pelas lentes de Thiago

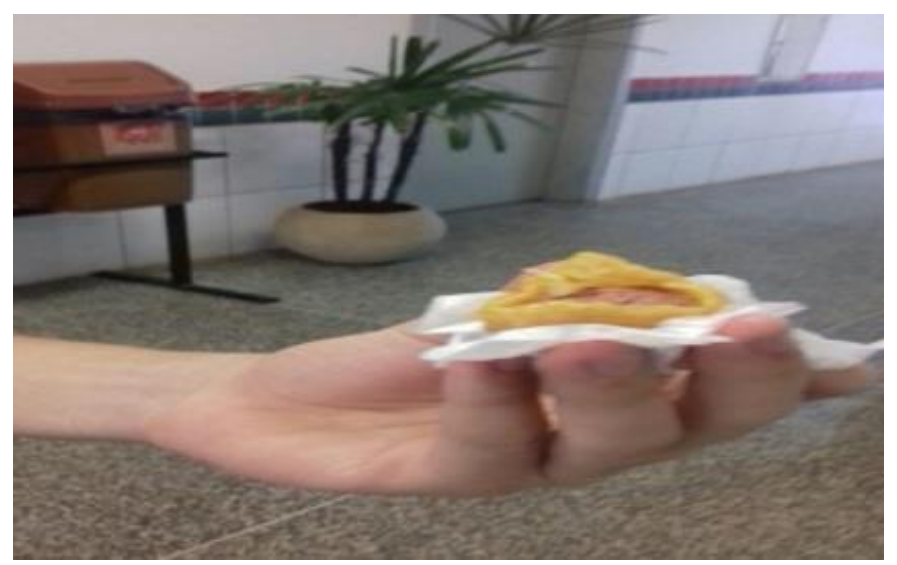

Fonte: Pesquisa de Campo, 2016.

Ainda sobre os recursos humanos e atendimentos disponibilizados aos alunos PAEE, consideramos relevante discutir a importância do Atendimento Educacional Especializado (AEE) no âmbito institucional. Os alunos não mencionam, nessa categoria o NAPNE, nem o AEE. Devemos nos lembrar de que o AEE deveria ser o espaço no qual os alunos PAEE encontrariam os recursos de acessibilidade.

O NAPNE teria a função de promover, assessorar e divulgar ações inclusivas, mas não caberia a ele a função do AEE, tanto que na composição do NAPNE não é obrigatória 
a existência do profissional especializado em Educação Especial, como se refere Art.12. da Resolução CNE/CEB № 4/2009, que Institui Diretrizes Operacionais para o Atendimento Educacional Especializado na Educação Básica, modalidade Educação Especial, "Para atuação no AEE, o professor deve ter formação inicial que o habilite para o exercício da docência e formação específica para a Educação Especial” (BRASIL, 2009, p.03).

Percebemos, pela fala dos alunos, que muitas ações de inclusão que caberiam ao AEE são realizadas no IFPR. Não de forma institucional, mas por iniciativa dos professores. Segundo pesquisa de Libório (2011) que analisou processos de resiliência em adolescentes em situação de risco, a autora verificou que o auxílio de pessoas da comunidade era mais presente que os programas do governo no que se refere aos recursos materiais. Entendemos que, na presente pesquisa, os serviços e recursos ofertados pelos professores são mais presentes e mais válidos aos alunos PAEE do que as ações institucionais em si, que deveriam ser desenvolvidas no AEE, se tal espaço existisse no IFPR.

Isso nos leva a concordar com Santos (2011), quando diz que a preocupação da instituição em procurar promover a inclusão deve ser igual perante todas as metas e ações que garantam a acessibilidade em todas as dimensões, para que o aluno com deficiência se desenvolva plenamente.

Para Mantoan et al. (2011) e Omote (2016) somente a oferta de estruturas físicas e equipamentos acessíveis não promovem a inclusão, é preciso uma mudança de pensamento e postura da comunidade escolar, que não diz respeito apenas em entender as características e necessidades dos alunos PAEE ou de como utilizar tais recursos, mas uma nova visão e prática de ensino e aprendizagem baseada em ações que respeitem as diferenças. Falta ainda por parte do IFPR fazer um trabalho para consolidar o NAPNE e, principalmente, o AEE, para que estes possam dar o suporte e capacitação necessária aos professores e à equipe pedagógica. Porém, apesar da falta do AEE se configurar como um indicador de risco, os alunos não consideram isso como um fator de risco, pois muito do que deveria ser feito pelo AEE está sendo realizado pelos professores.

\section{Justiça Social}

Para Ungar et al. (2008), essa tensão busca desenvolver no sujeito a resistência a preconceitos e a processos opressivos vivenciados em diferentes espaços, neste caso, o escolar. Essa tensão poderia se desenvolver por meio de ações da instituição que buscassem estimular o senso de justiça no aluno, ou seja, ações que façam com que os 
alunos PAEE se conscientizem e enfrentem os processos opressores, dificuldades ou problemas vivenciados na escola, podendo ser decorrentes ou não de sua limitação.

\section{Ações que conscientizem sobre atos opressores}

Nesta tensão, procuramos elucidar as dificuldades vivenciadas pelos alunos PAEE, e as ações institucionais que eram desenvolvidas para ajudar os alunos a superá-las. Os alunos relatam situações de injustiça que são gerados pelos colegas de classe. $\mathrm{O}$ aluno Dhiego menciona sentir-se alvo de preconceitos, por meio de comportamentos dos colegas que ele avalia como desprezo. Dhiego se sente impotente nessa situação e acredita que a instituição poderia conscientizar a comunidade acadêmica.

Catarina vivenciou situação não relacionada à sua deficiência, mas que considerou como "brincadeira" por parte dos colegas de classe, apesar de não gostar desse tipo de atitude. Percebe que na instituição é normal os alunos fazerem "brincadeiras" ridicularizando ou debochando dos colegas de classe, para a aluna, a instituição intervém nesse tipo de situação por meio dos professores que conversam e orientam os alunos. No entanto, em situações que deixam de ser "brincadeira" e passam a prejudicar o próximo, a aluna diz que sua iniciativa seria de defender a pessoa que está sofrendo o preconceito.

Willian diz sentir-se alvo de preconceitos, mas por não se importar com tais situações de discriminação, nunca comunicou ao IFPR. Apesar disso, considera que é necessário o IFPR fazer uma intervenção, conversando com os agressores. Situação está que já aconteceu com o aluno João, que sofreu bullying no IFPR por conta de sua deficiência. A equipe pedagógica tomou a iniciativa e fez uma intervenção, conversando sobre $o$ assunto com o agressor e o agredido.

Outras situações de preconceito e discriminação citadas pelos alunos como existente no IFPR se referem a ações cometidas pela própria instituição, como no caso da aluna Julia, que sente que seus direitos não são respeitados, pois quando não há intérprete de LIBRAS para fazer a interpretação das aulas, para a aluna não há aprendizado, uma vez que os professores não fazem nenhuma adaptação, dão a aula normalmente, esquecendo que há uma aluna surda na sala. Assim também, quando há outras atividades como palestras, o IFPR não leva em consideração a presença de alunos surdos e não disponibiliza a interpretação da palestra, o que nos demonstra que também falta por parte do IFPR trabalhar o respeito às diferenças com os professores. Nessa situação, percebemos que falta por parte da instituição IFPR um trabalho de transformação da 
mentalidade da comunidade escolar, que busque a internalização de práticas inclusivas (MANTOAN et al., 2011), pois apesar da proposta inclusiva, ações excludentes ainda são praticadas pelos professores.

No sentido de sofrerem injustiça dentro do IFPR, notamos que os alunos percebem as atitudes de discriminação de seus colegas devido à limitação deles. Nessas situações, os alunos relataram que o IFPR interviu com ações que conscientizassem os alunos sobre o respeito às diferenças. Apesar da ação de intervenção não acontecer por iniciativa dos alunos PAEE que foram injustiçados, consideramos que esses alunos se mostraram capazes de tomar essa iniciativa caso fosse preciso, pois desejam que seus direitos sejam respeitados e não se colocam como vítimas da situação. Isso nos leva a questionar o papel do IFPR no empoderamento desses alunos, para que possam buscar meios para resolver seus problemas, o que nos leva a considerar que as injustiças relatadas pelos alunos se configuram como fatores de risco aos alunos, pois, apesar da intervenção do IFPR, a instituição não está promovendo ações que façam os alunos tomarem a iniciativa de enfrentamento dessas situações.

Assim, percebemos que as ações de inclusão do IFPR contribuem para amenizar as situações de injustiça, mas não há ações que façam os alunos tornarem-se protagonistas no enfrentamento dessas situações. Segundo Cabral Filho e Ferreira (2013) isso ocorreria por meio do florescimento da participação social, que promove o enfrentamento e a possibilidade de negociação. É nesse sentido que protagonismo associa-se à resiliência. Assim consideramos que a tensão justiça social está atrelada ao desenvolvimento da tensão Poder e Controle, a qual será tratada na próxima categoria.

\section{Poder e Controle}

Esta tensão refere-se à capacidade interior e os recursos ao redor que as pessoas possuem, seja no campo material ou discursivo, em termos significativos para seu contexto, para tomada de decisões (PESSOA, 2011). Dessa forma analisamos quais ações do IFPR contribuíam para que o sujeito encontrasse ou fortalecesse sua capacidade para tomar decisões, ou seja, uma postura protagonista, assim como os recursos que a instituição oferecia para isso.

\section{Poder falar mas sem ser completamente ouvido}

Os alunos acreditam que o IFPR dá espaço para que se expressem no momento em que a própria instituição procura 0 aluno por meio dos professores e técnicos- 
administrativos e questiona sobre as dificuldades existentes e sobre formas de melhorar sua aprendizagem.

Maria, Catarina, Dhiego e Franklyn consideram que a instituição também está aberta para ouvi-los, apesar de não existir uma estrutura oficializada para isso. Esses alunos sentem-se à vontade para fazerem uma reclamação ou solicitarem algo, seja para o professor ou equipe pedagógica.

No caso do aluno Allan, que estava sem o intérprete de LIBRAS, o campus o auxiliou, por meio dos professores, a fazer a solicitação para a Reitoria do IFPR de outro intérprete de LIBRAS. Porém como não houve resposta, o aluno entrou com um processo contra o IFPR no Ministério Público Federal e até o momento da entrevista o processo ainda estava correndo.

Julia pensa em escrever um relatório abordando todos os problemas que vivencia, solicitando mudanças, pois ela já reclamou verbalmente para a coordenação do curso e para a seção pedagógica e nada foi feito.

Willian também fez solicitação para o IFPR, mas considera que os alunos não são totalmente ouvidos. Ele entende que os alunos possuem liberdade para fazerem as suas reclamações e reinvindicações, mas para serem atendidas é necessário mais que uma simples conversa.

De uma forma geral, os alunos não nos falaram de espaços ou momentos existentes no IFPR em que os alunos pudessem trabalhar e expor seu protagonismo. No ambiente escolar, consideramos que no Grêmio Estudantil os alunos poderiam desenvolver o senso crítico e participativo, pois o aluno seria responsável pelo seu aperfeiçoamento, descobriria seus anseios e desejos e compreenderia que somente de forma conjunta e organizada conseguiria atuar numa sociedade democrática (LUZ, 1998 apud GONZÁLEZ; MOURA, 2009). Trata-se de atitudes, valores e comportamentos representativos do protagonismo juvenil, entendidos como práticas essencialmente sensibilizadoras desse segmento da população (GONZÁLEZ; MOURA, 2009). Esse protagonismo possibilitaria aos alunos problematizar as necessidades presentes na escola e o desenvolvimento de um posicionamento maduro no seu convívio social.

Porém, quando as reivindicações não são atendidas, os alunos assumem uma postura protagonista, pois acabam se expressando seja no campo material, como o aluno Willian que, juntamente com os outros alunos, fez uma manifestação para que a sala em que 
estudavam fosse trocada, ou no campo discursivo, como os alunos Julia e Allan, que são surdos, que se prontificaram, respectivamente, a escrever um relatório para o coordenador do curso e a entrar com um processo no Ministério Público para que seus direitos fossem respeitados.

Porém, a partir da fala dos alunos, percebemos que o IFPR não oferece esses espaços participativos aos alunos, não incentivando o seu protagonismo, que lhes permitiria tornarem-se politicamente engajados em decisões relativas aos problemas de suas comunidades e de si próprios. Para Libório e Ungar (2013) o protagonismo contribui para 0 processo de resiliência, pois ajuda os jovens a valorizarem suas habilidades, proporciona um senso de pertencimento ao seu grupo e cultura, que faz com que busquem meios para contribuir para o bem-estar coletivo.

Portanto, ampliando as oportunidades que os adolescentes têm de participar em processos decisórios influentes, programas comunitários, programas sociais de interação e práticas culturais, é provável que o seu protagonismo aumente como sua capacidade de lidar com a adversidade (LIBÓRIO; UNGAR, 2013, p. 13 tradução nossa 14).

\section{Relacionamentos}

Nesta tensão procuramos analisar a percepção dos alunos PAEE sobre os relacionamentos interpessoais existentes no IFPR. Pesquisas que estudam o processo de resiliência no contexto escolar, como Libório (2009), Camargo (2009), Pessoa (2011) consideraram que os principais relacionamentos dos alunos nesse espaço seriam com os colegas de classe, professores e profissionais da escola. No caso desta pesquisa, que tem como lócus o IFPR e por estudar alunos PAEE, consideramos que as principais interações existentes seriam com os colegas de classe, com os professores e com os profissionais que compõem o NAPNE.

\section{Professores: suporte para aprendizagem}

Garcia (2008), Jones (2011) e Hartley (2013) falam sobre a importância do professor no processo de resiliência de alunos com deficiência, pois a forma de tratar e ensinar os alunos, promove oportunidades para que os alunos se encorajem, tenham confiança e autonomia.

Para os alunos, essa preocupação que os professores demonstram com relação a eles, contribui para o bom relacionamento entre eles. Segundo eles, os professores passam confiança e liberdade, mas o professor não é visto como alguém com quem poderiam 
desabafar sobre problemas pessoais, somente como alguém que ensina muito bem e se preocupa com o aprendizado do aluno.

Para Julia e para Dhiego, os professores também representam um suporte para aprendizagem. O que, para eles, acaba dificultando uma interação maior com os professores é que muitos nem tentam conversar com eles. A via de acesso é somente por meio do intérprete de LIBRAS.

Para Camargo (2009) não são necessárias soluções mágicas para propiciar um bom relacionamento professor-aluno, mas atitudes de respeito e preocupação podem se configurar enquanto importantes elementos protetores, fortalecendo e transmitindo confiança para o indivíduo. Ou seja, a relação professor-aluno também pode desenvolver processo de resiliência no momento em que os alunos sintam que os professores se preocupam com o aprendizado e o bem-estar escolar deles, o que condiz com os pressupostos de Garcia (2008), Jones (2011) e Hartley (2013) para os quais o apoio dos professores e a forma de ensinar que busquem a confiança e autonomia do aluno contribuem para o processo de resiliência. E, novamente para os alunos surdos, apesar de o IFPR oferecer o curso de LIBRAS, percebemos que poucos professores o fazem devido à dificuldade que esses alunos relatam de se comunicarem com os professores.

Como ação institucional não há nada que sensibilize os professores a se tornarem uma referência de apoio aos alunos PAEE, como defendem Firth et al. (2013). Os pesquisadores apresentam, em sua pesquisa, a importância dos professores da instituição receberem um curso para entenderem a deficiência atendida, melhorando a sua performance em sala de aula, e também o desempenho dos alunos, pois passam a considerar as dificuldades dos alunos PAEE como culturalmente importantes no processo ensino-aprendizagem. Capacitar e sensibilizar os professores possibilita um maior comprometimento por parte deles em buscar formas de ensinar, como também os tornam mais conscientes de como seus comportamentos afetam esses alunos (ORR; GOODMAN, 2010; ALLSOPP et al., 2005).

\section{Colegas de classe: suporte para aprendizagem e para questões emocionais}

Os alunos consideram que a relação com os colegas de classe em geral é muito boa e mostrando-se como um importante fator de proteção dentro da instituição, pois, pelas fotografias, todos os alunos registraram momentos em que estavam interagindo com os colegas, seja em trabalho de sala de aula ou em projetos de pesquisa, como também a 
própria foto do seu colega como registros de que mais gostaram ou que representam algo bom na vida e na escola.

Percebemos que a importância do relacionamento com os colegas de classe fundamentou-se em dois aspectos: o primeiro é que a relação se baseia somente no apoio para aprendizagem e o outro é que a relação abrange a dimensão da aprendizagem, mas também funciona como suporte emocional para assuntos fora do contexto escolar.

Notamos os casos dos alunos PAEE para quem, além desse suporte para a aprendizagem, o apoio dos colegas de classe tornou-se essencial, visto que, com a ajuda deles, os alunos com deficiência conseguem se comunicar e se locomover no espaço escolar. Para a aluna Julia, o suporte dos colegas de classe na sua aprendizagem tornouse imprescindível, pois devido à falta de adequações dos professores para ensinar, quando a intérprete de LIBRAS não está presente, a aluna acabava dependendo da interpretação dos seus colegas de classe, que começaram a aprender LIBRAS, ensinada por Júlia. A aluna fotografou a colega que sempre a ajuda a se comunicar com as outras pessoas, incluindo atividades como comprar algo na cantina ou solicitar algum documento na secretaria escolar. Para o aluno Fabio, o fato do IFPR ofertar o curso de LIBRAS, ajuda na promoção desse relacionamento, pois a comunicação passa a ser facilitada. Para o Franklyn, o apoio dos colegas de classe também se tornou fundamental, pois ele depende de seus colegas para descrever os espaços a fim de se locomover pela instituição.

Duas ações institucionais foram citadas pelos alunos como contribuindo para melhorar o relacionamento com os colegas de classe. Uma delas foi a oferta do curso de LIBRAS aos alunos em geral. Entretanto, em decorrência da dificuldade de comunicação alegada pelos alunos surdos, acreditamos que tal curso não tenha interessado aos alunos ou não tenha sido bem divulgado. Outra ação institucional que contribui para melhorar o relacionamento entre os alunos seria os eventos institucionais que buscam reunir os alunos da instituição numa proposta mais cultural, permitindo-Ihes terem outros tipos de contatos entre eles além do suporte para aprendizagem, promovendo outros tipos de interações entre os alunos PAEE, os demais alunos da instituição e os professores. Fee e Hilton (2011), Resende e Gouveia (2011), Migerode et al. (2012) consideram o apoio social um forte aliado no processo de resiliência, pois além do suporte emocional revelam a questão da aceitação social da sua comunidade.

\section{NAPNE: atividades camufladas}


Com relação aos alunos, verificamos que dos doze alunos participantes, somente dois conheciam o NAPNE, mas um não sabia exatamente sua função, só sabia dizer quem fazia parte.

Acreditamos que a falta de conhecimento do NAPNE pelos alunos se deve à ausência de atividades executadas por esse núcleo ou então à falta de divulgação ou esclarecimento das suas ações, pois muitos alunos comentam que contam com o apoio da pedagoga, da psicóloga do IFPR, que muitas vezes fazem parte do NAPNE, ou seja, apesar do NAPNE não ser conhecido pelos alunos PAEE, estes são assistidos pelo núcleo, mas não sabem, pois quem compõe o NAPNE e a equipe pedagógica muitas vezes pertencem à mesma equipe.

Apesar dessa combinação de funções do NAPNE e equipe pedagógica, percebemos que a atuação do NAPNE no desenvolvimento de ações inclusivas é mínima, pois foram poucos os alunos que relataram sobre atividades relacionadas à inclusão. $O$ que podemos registrar no que se refere ao NAPNE e seu relacionamento com os alunos são as ações desenvolvidas pela pedagoga e psicóloga que conversam com os alunos e os orientam sobre as suas dificuldades. Já os intérpretes de LIBRAS são considerados pelos alunos surdos um forte ponto de apoio, existindo até mesmo uma grande dependência dos alunos por esse profissional.

A presença de um vínculo maior dos alunos PAEE com o intérprete de LIBRAS e as pedagogas pode ser relacionada com a ideia apresentada por Catusso (2007) sobre o "tutor da resiliência", que seria a pessoa responsável por potencializar as capacidades dos alunos, oferecendo suporte para a compreensão e superação das adversidades.

Apesar da maioria das ações inclusivas descritas na tensão relacionamentos serem promovidas pelos professores, equipe pedagógica e intérprete de LIBRAS, adquirindo uma dimensão mais pessoal (pelo interesse dos profissionais) do que institucional, para Sousa (2008), o fato de as relações existentes no ambiente escolar estimularem interações que contribuam para o sucesso dos alunos, estimulando-os a se sentirem capazes, auxilia o aluno a encontrar formas de superar suas dificuldades.

\section{Identidade}

Para Ungar et al. (2007) esta tensão está relacionada à capacidade do sujeito de reconhecer suas habilidades e limitações por meio de interações intrapessoais e 
interpessoais. Buscamos identificar as ações institucionais que contribuíam para que os alunos PAEE desenvolvessem uma identidade positiva.

\section{A motivação institucional e participação em atividades valorizadas pela comunidade acadêmica}

A motivação feita pelos professores é citada pelos alunos como contribuindo para que os mesmos não desistam, como por exemplo, as dificuldades no aprendizado nas disciplinas escolares faz com que desanimem. Alguns participantes da pesquisa consideram que, para melhorarem o rendimento, é necessário que o esforço e dedicação parta deles. Por outro lado, segundo os alunos, o IFPR oferece algumas ações que os ajudam nesse processo (de busca deste esforço) e dão como exemplos: os atendimentos oferecidos pelos professores no contraturno, que são momentos em que podem estudar junto com os professores e esclarecer as dúvidas, as palavras de motivação dos professores, pedagoga e intérprete de LIBRAS para que os alunos superem suas dificuldades se esforçando e se dedicando mais aos estudos.

A possibilidade de participarem das atividades que gostam fazem com que os alunos se sintam capazes de realizar todas as atividades da instituição, porque possuem consciência das suas limitações e buscam se esforçar diante das dificuldades ocasionadas pela deficiência, considerando que, se precisarem, terão a ajuda dos professores e colegas de classe. Uma atitude que contribui para isso é o fato dos professores não tratá-los de forma diferente, pois não os favorecem no sentido de facilitar as atividades para eles. Os professores permitem que, apesar das dificuldades com relação às atividades propostas, os alunos com deficiência tentem fazê-las, oferecendo ajuda quando necessário.

O IFPR incentiva a participação dos alunos PAEE em atividades que necessitam da interação interpessoal, como as atividades esportivas, que proporcionam aos alunos um melhor relacionamento com os colegas de classe, professores e também com suas limitações, contribuindo para a formação de uma identidade positiva, pois o aluno passa a ser visto e reconhecido pelo seu esforço e dedicação, e não por sua limitação. Como no caso do aluno Franklyn, que foi convidado pelo professor a participar de atividades esportivas, dentro dos limites de sua capacidade, tendo suas limitações respeitadas.

A importância do IFPR e dos professores respeitarem as diferenças dos alunos quando estes participam das diversas atividades, ajudando-os quando eles precisam, contribui para o desenvolvimento de uma identidade positiva. Para Oliveira e Rodrigues 
(2011) esse tipo de ação que permite a participação dos alunos em todas as atividades não significa negar a deficiência, mas sim acreditar que diferenças exigem diferentes intervenções pedagógicas e diferentes olhares, contudo, sem diminuir o que se pode ensinar, subestimando o aluno e suas reais possibilidades.

\section{Coesão}

A tensão Coesão refere-se ao papel desempenhado pelo sujeito dentro de um contexto ou cultura, a partir da qual buscamos analisar as ações do IFPR que contribuem para que o sujeito desenvolva atividades ou ações que beneficiem não somente a ele, mas a toda comunidade também.

\section{Sentir-se acolhidos pela instituição}

Percebemos, na fala dos alunos, que os professores buscam inteirá-los a respeito dos problemas vivenciados, pedindo a sua opinião e ajuda para solucionarem os problemas, ou então, incentivando os alunos a ajudarem seus colegas em atividades em que já tenham mais domínio. Para Libório (2011) quando há relações que passam calor humano e segurança aos indivíduos dentro da sua comunidade, a resposta desses indivíduos será a reprodução desses sentimentos e ações. Essa ação mostra aos alunos que a instituição se importa com eles, e tal atitude os estimula a contribuir e ajudar.

Para Didkowsky et al. (2010) e Libório (2011), nos casos em que os sujeitos sentem que são valorizados, que sua contribuição se torna útil para a comunidade, por meio das relações que são vivenciadas nessa comunidade, os indivíduos passam a querer retribuir/devolver da mesma forma para sua comunidade.

\section{Palestras de conscientização}

Vimos que outra forma pela qual o IFPR está ajudando a desenvolver essa tensão é por meio de palestras que conscientizem os alunos da importância da preocupação com a comunidade escolar.

Essa ação citada pelos alunos pode estar contribuindo para que eles passem a ter uma preocupação com o coletivo escolar, conscientizando os alunos sobre a preocupação com o espaço escolar e com o próximo. Apesar de essas ações serem destinadas a todos os alunos, contribuem para a inclusão do aluno PAEE, pois promovem o senso de pertencimento à comunidade, colaborando para o processo de resiliência. As ações mencionadas neste tópico partem mais da iniciativa pessoal dos professores, não tendo sido proposta nenhuma ação por parte do IFPR que motivasse os professores a agirem 
assim ou a desenvolverem atividades que contribuíssem para o pensamento coletivo. Percebemos, portanto, que professores e equipe pedagógica desenvolveram tais ações por sentirem necessidade.

\section{Aderência Cultural}

Esta tensão relaciona-se com a questão do indivíduo concordar ou não com as normas culturais, crenças e valores da comunidade escolar. Para isso é necessária uma complexa negociação entre esse indivíduo e a comunidade escolar. Procuramos analisar a fala dos alunos, verificando como a cultura da inclusão está sendo trabalhada na instituição.

\section{Ações docentes promovem a cultura inclusiva}

Os alunos não conseguem ter a dimensão se as ações que os favorecem são institucionais ou não, para eles, apesar do IFPR não fazer nenhuma ação específica para promover a cultura inclusiva, como um dia da inclusão ou o dia da pessoa com deficiência, a maioria dos alunos acreditam que a instituição é inclusiva e se sentem incluídos, devido à existência de ações e atitudes que os fazem sentir que suas diferenças, decorrentes da deficiência, são respeitadas. Percebem que os desafios a serem superados não são somente da parte deles, pois os professores também estão superando os desafios com eles.

Para Julia e Dhiego, apesar de não achar o IFPR uma instituição inclusiva, ela considera que das escolas em que estudou, o IFPR, apesar de todos os problemas como falta de intérprete, falta de comunicação com os servidores devido ao desconhecimento da LIBRAS, ainda é a melhor escola devido à educação que é ofertada e às atividades diferenciadas como o atendimento do professor no contraturno e os projetos de pesquisa.

Os demais alunos consideram que é melhor estudar no IFPR do que em outras escolas, principalmente pelas atividades extras que oferecem, como o contraturno e o atendimento que é ofertado por meio da equipe pedagógica, além da preocupação dos professores com seu aprendizado.

Somente Franklyn mencionou a ocorrência de ações que promoviam a cultura inclusiva no IFPR, como o evento cuja palestrante era alguém ligada a assuntos sobre pessoas com deficiência, a possibilidade do IFPR promover um evento cultural cujo tema seria a inclusão, e no qual ele estaria disposto a contribuir por meio de uma palestra, e também trabalhos de sala de aula sobre a inclusão e acessibilidade. 
Para Camargo (2009) e Libório (2011) a aderência cultural relaciona-se com aderir ou se opor à cultura local/global, podendo ser tanto uma barreira como um caminho viável para resiliência, dependendo da relação entre essa tensão e as outras. Ou seja, apesar do IFPR quase não desenvolver ações específicas que desenvolvam a cultura inclusiva, as outras ações que trabalham as demais tensões, como tratamento igualitário, participação em atividades valorizadas pela comunidade escolar, sentir-se parte da instituição, relacionamentos que oferecem suporte, fazem os alunos PAEE conseguirem transitar pelos valores e princípios institucionais, fazendo-os se sentir incluídos.

Dessa forma, a cultura inclusiva não está sendo criada por ações do IFPR, pois as ações que estariam promovendo uma cultura inclusiva partem de iniciativa dos professores que, de certa maneira, fazem com que a maioria dos alunos se sinta incluída, mas muito precisa ser melhorado, principalmente com relação aos alunos surdos. Assim, existe um descompasso entre a inclusão que os alunos querem e precisam e a inclusão que o IFPR oferece.

\section{Considerações Finais}

Consideramos que faltam ações e políticas institucionais que trabalhem valores e princípios que promovam realmente a cultura inclusiva. Principalmente com relação aos alunos surdos, que das deficiências entrevistadas, foram os alunos que encontramos mais em situação de risco dentro do IFPR, pois a maioria das ações, sejam institucionais ou realizadas pelos professores e equipe pedagógica, não os atendia plenamente, evidenciando que o IFPR não está realmente incluindo o aluno surdo. O principal problema para se sentirem incluídos seria a dificuldade na comunicação com os professores, colegas de classe e com os outros setores, como cantina, secretaria. O IFPR disponibiliza o curso de LIBRAS, mas não é feito um trabalho de conscientização para os professores e alunos participarem.

Dessa forma, o IFPR, pelas suas ações institucionais não está fomentando a prática da inclusão, uma que vez que não está cumprindo o disposto na LDB no 9394/96 (BRASIL, 1996) sobre a Educação Especial, em que se devem assegurar técnicas e recursos educativos que atendam às necessidades dos alunos, situação que não está sendo ofertada aos alunos surdos, pois nem todos estão acompanhados pelo intérprete de LIBRAS, e o IFPR alega a falta de verbas para isso. Isso pode até ser uma realidade, mas não cabe ao aluno surdo o enfrentamento de um problema ocasionado pela falta de 
planejamento orçamentário da instituição. Além disso, constatamos a inexistência do AEE, que segundo os documentos Política Nacional da Educação Especial na Perspectiva da Educação Inclusiva (BRASIL, 2008), Resolução CNE/CEB № 4/2009, o Decreto no 7.611/2011 deve ser ofertado de forma obrigatória pelos sistemas de ensino, seja na própria escola ou em centros especializados. Mas pelo fato de nenhum aluno fazer citação a esse atendimento, acreditamos que o IFPR não o oferece em seu âmbito, como também não buscou parcerias com outras instituições de ensino conforme regulamentado pelas normativas. Assim, torna-se difícil uma instituição de ensino praticar e desenvolver uma cultura inclusiva quando não consegue cumprir as normativas básicas referentes à educação especial na perspectiva da educação inclusiva.

Com relação aos alunos PAEE, apesar das ações de inclusão desenvolvidas, alguns fatores de risco estavam presentes, pois as ações de inclusão não atendiam a todos os alunos, principalmente aos alunos surdos, fazendo, em muitas situações, esses alunos se sentirem excluídos. Além disso, as ações de inclusão, sejam institucionais ou por iniciativa docente, não favoreciam diretamente a resolução das tensões Justiça Social e Poder e Controle. Por isso, torna-se urgente a consolidação do NAPNE e do AEE pelo IFPR, fomentando pessoas, espaços e momentos em que os alunos PAEE possam se referenciar, para que encontrem meios de reivindicar por seus direitos, trabalhando-se a postura protagonista na resolução dos problemas e conflitos que surgirem. Dessa forma, no IFPR o processo de inclusão não está instituído, mas se encontra em processo.

\section{Referências}

ALLSOPP, David.; MINSKOFF, Esther.; BOLT, Les. Individualized course-specific strategy instruction for college students with learning disabilities and ADHD: Lessons learned from a model demonstration process. Learning Disabilities Research and Practice, v.20, p.103118, 2005.

BRASIL. Lei no 9394, de 20 de dezembro de 1996. Estabelece as diretrizes e bases da educação nacional. Disponível em: http://www.planalto.gov.br/legislacao. Acesso em 06 Abr. 2015.

BRASIL. Decreto no 5296, de 2 dezembro de 2004. Regulamenta as Leis no 10.048 , de 8 de novembro de 2000 , que dá prioridade de atendimento às pessoas que especifica, e 10.098, de 19 de dezembro de 2000, que estabelece normas gerais e critérios básicos para a promoção da acessibilidade das pessoas portadoras de deficiência ou com mobilidade reduzida, e dá outras providências. Disponível on-line: 
http://portal.mec.gov.br/seesp/arquivos/pdf/decreto\%205296-2004.pdf. Acesso em: 17 fev. 2017.

BRASIL. Política Nacional de Educação Especial na Perspectiva da Educação Inclusiva. Brasília: MEC, 2008.

BRASIL. Resolução CNE/CEB no 4, de 2 de outubro de 2009. Institui Diretrizes Operacionais para o Atendimento Educacional Especializado na Educação Básica, modalidade Educação Especial. Brasília: MEC/CNE/CEB, 2009. Disponível em: http://portal.mec.gov.br/dmdocuments/rceb004_09.pdf. Acesso em 27 Fev. 2017.

BRASIL. Decreto no 7.611, de 17 de novembro de 2011. Dispõe sobre a educação especial, o atendimento educacional especializado e dá outras providências. Disponível em: http://www.planalto.gov.br/ccivil_03/_Ato2011-2014/2011/Decreto/D7611.htm\#art11.

Acesso em 25 Nov. 2015.

BRASIL. Lei no 12.764, de 27 de dezembro de 2012. Institui a Política Nacional de Proteção dos Direitos da Pessoa com Transtorno do Espectro Autista; e altera o § $30 d o$ art. 98 da Lei no 8.112, de 11 de dezembro de 1990. Disponível em: http://www.planalto.gov.br/ccivil_03/_ato2011-2014/2012/lei/l12764.htm. Acesso em 25 Nov. 2015.

BRASIL. Ministério da Educação. Secretaria de Educação Profissional e Tecnológica. Ação TEC NEP - Relação de Núcleos de Atendimento às Pessoas Com Necessidades Educacionais Específicas. Brasília, DF, 2012b. Disponível em: http://portal.mec.gov.br/index.php?option=com_docman\&view=download\&alias=7542napne-setec\&category_slug=fevereiro-2011-pdf\&Itemid=30192. Acesso em 26 de Fev. 2019.

CABRAL FILHO, Adilson Vaz; FERREIRA, Gildete. Movimentos sociais e o protagonismo das pessoas com deficiência. SER Social. Brasília, v.15, n.32, p.93-116, jan./jun. 2013.

CAMARGO, Luciene dos Santos. Concepções de adolescentes sobre a escola: do risco à proteção. 2009. 161f. Dissertação (Mestrado em Educação). Universidade Estadual Paulista. Faculdade de Ciência e Tecnologia, Presidente Prudente.

CATUSSO, Renata Lobo. A Resiliência e a Imagem Corporal de Adolescentes e Adultos com Mielomeningocele. 2007. 83f. Dissertação (Mestrado em Educação Física)Faculdade de Educação Física. Universidade Estadual de Campinas, Campinas. 
CARDOSO, Fernando Luiz.; SACOMORI, Cinara. Resilience of athletes with physical disabilities: a cross-sectional study. Revista de Psicología del Deporte. v.23, n. 1, p.1522, 2014.

DIDKOWSKY, Nora.; UNGAR, Michael.; LIEBENBERG, Linda. The negotiating resilience project - research report. Relatório de Pesquisa não publicado. Dalhousie University, Halifax, CA, 2010.

FEE, Robert J.; HINTON, Veronica J. Resilience in Children Diagnosed with a Chronic Neuromuscular Disorder. J Dev Behav Pediatr. n.32, v.9, p.644-650, 2011.

FIRTH, Nola.; FRYDENBERG, Erica; STEEG, Charlotte; BOND, Lyndal. Coping successfully with dyslexia: an initial study of an inclusive school-based resilience programme. Dyslexia. v.19, p.113-130, 2013.

GALVÃO FILHO, Teófilo. A. Tecnologia assistiva para uma escola inclusiva: apropriação, demanda e perspectivas. 2009. 346p. Tese (Doutorado em educação). Universidade Federal da Bahia - Faculdade de Educação, Bahia.

GARCIA, Silvana Canalhe. A resiliência no indivíduo especial: uma visão logoterapêutica. Revista Educação Especial. n.31, Santa Maria. p. 25-36, 2008.

GONZÁLEZ, Jorge Luis Cammarano; MOURA, Marcilene Rosa Leandro. Protagonismo juvenil e grêmio estudantil: a produção do indivíduo resiliente. EccoS, São Paulo, v.II, n.2, p.375-392, jul./dez., 2009.

HARTLEY, Michael. T. Investigating the relationaship of resilience to academic persistence in college students with mental health issues. Rehabilitatiion counseling bulletin. v.56, n. 4 , p.240-250, 2013.

JONES, Vita L. Resiliency instructional tactics: African American students with learning disabitities. Intervention in school and clinic. v.46, n.4, p.235-239, 2011.

LIBÓRIO, Renata Maria Coimbra. Escola: risco, proteção e processos de resiliência durante a adolescência, 2009. Disponível on-line http://www.anped.org.br/reunioes/32ra/arquivos/trabalhos/GT20-5283--Int.pdf. Acesso em 09 de janeiro 2013.

LIBÓRIO, Renata Maria Coimbra. Negociando resiliência: processos protetivos de adolescentes em contextos potenciais de risco - FAFESP - Relatório científico final. Presidente Prudente, 2011. 
LIBÓRIO, Renata Maria Coimbra; UNGAR, Michael. Resilience as protagonism: interpersonal relationships, cultural practices, and personal agency among working adolescents in Brazil. Journal of Youth Studies, 2013. Disponível em <http://dx.doi.org/10.1080/13676261.2013.834313> Acesso em 11 de Maio de 2017.

LIBÓRIO, Renata Maria Coimbra.; CASTRO, Bernardo Monteiro; FERRO, Elaine Gomes; SOUZA, Marilza Terezinha Soares. Resiliência e processos protetivos de adolescentes com deficiência física e surdez incluídos em escolas regulares. Revista Brasileira de Educação Especial. Marília. v.21, n.2, p.185-198, 2015.

MANTOAN, Maria. Teresa Eglér; ROPOLI, Edilene Aparecida; SANTOS, Maria Terezinha da Consolação Teixeira dos; MACHADO, Rosângela. A educação especial na perspectiva da inclusão escolar: a escola comum inclusiva. A educação especial na perspectiva da Inclusão escolar. Ministério da Educação/ Secretaria da Educação Especial. 2011.

MIGERODE, Femke; MAES, Bea; BUYSSE, Ann; BRONDEEL, Ruben. Quality of life in adolescents with a disability and their parents: the mediating role of social support and resiliência. J. Dev. Phys Disabil. Bélgica. n.24. p. 487-503, 2012.

OLIVEIRA, Marinalva Silva; RODRIGUES, Lidiane Furtado Ferreira. A inclusão no Ensino Superior: uma experiência em debate! PRACS: Revista de Humanidades do Curso de Ciências Sociais da UNIFAP. Macapá, n.4, p.17-28, dez. 2011.

OMOTE, Sadao. Atitudes em relação à inclusão no Ensino Superior. Journal of Research in Special Education Needs. v. 16, n. 51, p.211-215, 2016

ORR, Ann C.; GOODMAN, Nicole. People like me don't go to college: the legacy of learning disability. Journal of ethnographic \& qualitative research. v.4, p.213-225, 2010.

PESSOA, Alex Santos Gomes. O papel da escola na vida de adolescentes vítimas de violência sexual: risco e proteção. 2011. 122f. Dissertação (Mestrado em Educação). Faculdade de Ciência e Tecnologia, Presidente Prudente.

RESENDE, Marineia Crosara de; GOUVEIA, Valdiney Veloso. Qualidade de vida em adultos com deficiência física. Psicologia: Reflexao \& Critica. v.24. n.1, p.99-106. Jan.-Mar. 2011

SANTOS, Yvonete Bazbuz da Silva. As políticas públicas de educação para a pessoa com deficiência: a proposta desenvolvida nos Institutos Federais de Educação, Ciência e Tecnologia. 2011. 109f. Dissertação (Mestrado em educação). Universidade Federal do Ceará, Faculdade de Educação, Fortaleza. 
SARTORETTO, Maria Lúcia. Os Fundamentos da Educação Inclusiva. 2011. Disponível em: http://assistiva.com.br/Educa\%C3\%A7\%C3\%A3o_Inclusiva.pdf. Acesso em: 14 Mar. 2015.

SCHMIDT, Ann Alriksson.; WALLANDER, Jan; BIASINI, Fred. Quality of life and resilience in adolescents with a mobility disability. Journal of pediatric psychology. v. 32. n.3, p.370379, 2007.

SIMÕES, Celeste.; MATOS, Margarida Gaspar de; FERREIRA, Mafalda; TOMÉ, Gina. Risco e resiliência em adolescentes com necessidades educativas especiais: desenvolvimento de um programa de promoção da resiliência na adolescência. Psicologia, Saúde \& Doenças. v.11, n.1, p.101-119, 2010.

SOUSA, Carolina Silva. Competência educativa: o papel da educação para a resiliência. Revista Educação Especial. Santa Maria. n. 31, p.09-24, 2008.

UNGAR, Michael. Contextual and cultural aspects of resilience in child welfare settings. In: BROWN, I.; CHAZE, F.; FUCHS, D.; LAFRANCE, J.; MCKAY, S.; PROKP, S. T. (Eds.), Putting a human face on child welfare: Voices from the Prairies. Regina, Canada: Prairie Child Welfare Consortium, p.1-23, 2007.

UNGAR, Michael; BROWN, Marion; LIEBENBERG, Linda; OTHMAN, Rasha; KWONG, Waiman; ARMSTRONG, Mary; GILGUN, Jane. (2007). Unique pathways to resilience across cultures. Adolescence, v.42, n.16, p.287-310, 2007.

UNGAR, Michael.; LIEBENBERG, Linda.; THERON, Linda;. Distinguishing differences in pathways to resilience among Canadian youth. Canadian Journal of Community Mental Health, v. 27, n.1, p.1-13, 2008.

UNGAR, Michael.; THERON, Linda.; DIDKOWSKY, Nora. Adolescent's precocious and developmentally appropriate contributions to their families well-being and resilience in five countries. Family Relations, v.60, p.231-246, 2011.

YUNES, Maria Angela Mattar; SZYMANSKI, Heloisa. Resiliência: noção, conceitos afins e considerações críticas. In: TAVARES, J. (Org.). Resiliência e Educação. São Paulo: Cortez Editora, 2001, p. 13-42.

\section{Correspondência}

Thais Watakabe Yanaga - Instituto Federal do Paraná - Avenida José Felipe Tequinha, 1400. Paranavaí. CEP: 87703-536. Paranavaí, Paraná, Brasil. 


\section{(c) $($ i) (9)}

This work is licensed under a Creative Commons Attribution-NonCommercial 4.0 International (CC BY-NC 4.0) 